\title{
Conselho de alimentação escolar (CAE): os desafios enfrentados pelos conselheiros
}

\author{
School food council (CAE): the challenges faced by councilors \\ Consejo de alimentos escolares (CAE): los desafíos de los consejeros
}

\author{
Genyvana Criscya Garcia Carvalho \\ ORCID: https://orcid.org/0000-0002-8151-8746 \\ Universidade Paulista, Brasil \\ E-mail: genyvanacarvalho@icloud.com \\ Ivonalda Brito de Almeida Morais \\ ORCID: https://orcid.org/0000-0002-1306-7568 \\ Universidade Paulista, Brasil \\ E-mail: ivonaldaa@gmail.com.br \\ Guilherme Antônio Lopes de Oliveira \\ ORCID: https://orcid.org/0000-0003-3820-0502 \\ Cristo Faculdade do Piauí, Brasil \\ E-mail: guilhermelopes@live.com \\ Oduvaldo Vendrametto \\ ORCID: https://orcid.org/0000-0003-2430-6138 \\ Universidade Paulista, Brasil \\ E-mail: oduvaldov@gmail.com
}

\begin{abstract}
Resumo
A alimentação escolar tem como objetivos contribuir para aumentar as condições nutricionais dos estudantes, efetivar a sua permanência, promover a educação alimentar, também contribuir para a melhoria do processo de ensinoaprendizagem e, consequentemente, para a diminuição dos índices de evasão e repetência escolar. A alimentação escolar é uma questão vital, pois a alimentação escolar agrega também valores, tais como formação de hábito e atitudes alimentares. Esse artigo tem o objetivo discorrer sobre o Conselho de Alimentação Escolar (CAE) em seus aspectos conceituais, legais e desafios no desenvolvimento das atribuições dos conselheiros. É um estudo de revisão bibliográfica, onde foram utilizados sites de busca, como Google Acadêmico e SCIELO, através das palavras-chave: alimentação escolar, Conselho de alimentação escolar e Desafios. Com a pesquisa, foi possível levantar os dados que subsidiam esse estudo. Conclui-se como principal desafio a falta de preparação e conhecimento da legislação sobre o Programa Nacional de Alimentação Escolar (PNAE), uma vez que na prática não são ofertados cursos voltados para a preparação dos conselheiros para atuar no CAE, e são muitas as atribuições referentes às atividades dos conselheiros. São desafios ainda a falta de estrutura para a realização das reuniões e falta de transporte para visita às escolas, o que acaba cerceando o objetivo do CAE e consequente execução no PNAE.
\end{abstract}

Palavras-chave: Alimentação escolar; Conselho de alimentação escolar; Desafios.

\begin{abstract}
School feeding aims to contribute to increase the nutritional conditions of students, make them stay in school, promote food education, also contribute to the improvement of the teaching-learning process and, consequently, reduce dropout and repetition rates. School feeding is a vital issue, as school feeding also adds values, such as the formation of eating habits and attitudes. This article aims to discuss the School Meals Council (CAE) in its conceptual, legal and challenges aspects in the development of the duties of the counselor. For This is a study of bibliographic review, where search sites, such as Google Scholar and SCIELO, were used, using the keywords: school meals, school feeding council. Challenges, with the research it was possible to raise the data that support this study. The main challenge is the lack of preparation and knowledge of the legislation of the National School Feeding Program (PNAE), since in practice there are no courses aimed at preparing counselors to work at the CAE, with many attributions regarding the work of the CAE directors. The challenges are still the lack of structure to hold meetings and the lack of transportation for visits to schools, which ends up hindering the CAE's objective and consequent execution in the PNAE.
\end{abstract}

Keywords: School feeding; School feeding council; Challenges.

\section{Resumen}

La alimentación escolar tiene como objetivo contribuir a incrementar las condiciones nutricionales de los estudiantes, efectuar su permanencia, promover la educación alimentaria, contribuir también a la mejora del proceso de enseñanzaaprendizaje y, en consecuencia, a la reducción de las tasas de deserción y repetición. La alimentación escolar es un tema vital, ya que la alimentación escolar también agrega valores, como la formación de hábitos y las actitudes 
alimentarias. Este artículo tiene como objetivo discutir el Consejo Escolar de Alimentación (CAE) en sus aspectos conceptuales, legales y desafíos en el desarrollo de las funciones de los orientadores. Se trata de un estudio de revisión bibliográfica, donde se utilizaron sitios de búsqueda, como Google Scholar y SCIELO, a través de las palabras clave: comidas escolares, Consejo de alimentación escolar y Desafíos. Con la investigación se logró recabar los datos que sustentan este estudio. El principal desafío es la falta de preparación y conocimiento de la legislación sobre el Programa Nacional de Alimentación Escolar (PNAE), ya que en la práctica no existen cursos dirigidos a preparar a los orientadores para trabajar en el CAE, y hay muchas atribuciones respecto a las actividades de los directores. Los desafíos siguen siendo la falta de estructura para realizar reuniones y la falta de transporte para visitar las escuelas, lo que termina por coartar el objetivo del CAE y consecuente ejecución en el PNAE.

Palabras clave: Alimentación escolar; Consejo de alimentación escolar; Desafíos.

\section{Introdução}

O Programa Nacional de Alimentação Escolar (PNAE) oferece orientação, recursos e ações de educação alimentar e nutricional às escolas para que elas propiciem aos estudantes da educação básica pública e privada assistencial a alimentação escolar. Os recursos do referido programa do Governo Federal são repassados para estados, municípios e união para suplementar os gastos com a Alimentação Escolar- AE. Tais recursos proveem do Fundo Nacional de Desenvolvimento Escolar (FNDE, 2020).

De acordo com o FNDE (2020), o valor repassado pela União a estados e municípios por dia letivo para cada aluno é definido de acordo com a etapa e modalidade de ensino: Creches: R\$ 1,07; Pré-escola: R\$ 0,53; Escolas indígenas e quilombolas: $\mathrm{R} \$ 0,64$; Ensino fundamental e médio: $\mathrm{R} \$ 0,36$; Educação de jovens e adultos: $\mathrm{R} \$ 0,32$; Ensino integral: $\mathrm{R} \$ 1,07$; Programa de Fomento às Escolas de Ensino Médio em Tempo Integral: R 2,00 e Alunos que frequentam o Atendimento Educacional Especializado no contraturno: R $\$ 0,53$.

Em 2017, o PNAE atendeu 41 milhões de estudantes da educação básica com investimento de R \$ 3,90 bilhões, com incremento de 10,8\% em relação a 2016 (FNDE, 2018). Em 2015, o número de municípios atendidos pelo PNAE foi 5262 (FNDE, 2017b) do total de 5570 municípios brasileiros (IBGE, 2019).

Segundo informações do FNDE (2019), o PNAE acompanha os dados e informações, e a fiscalização quanto à execução, qualidade, regularidade compete ao CAE - Conselhos de Alimentação Escolar (CAE). Sob os aspectos financeiros e procedimentos legais, a supervisão e fiscalização são realizadas pelo FNDE, Tribunal de Contas da União (TCU), Controladoria Geral da União (CGU) e pelo Ministério Público.

O repasse é enviado aos estados e municípios, e toma por base o Censo Escolar realizado no ano anterior. Os recursos repassados pelo FNDE são complementares àqueles que municípios, estados e outros beneficiários já dispendem. O CAE, responde oficialmente, portanto, pelos recursos provindos do FNDE. Muitos municípios, entretanto, só se utilizam dos recursos do FNDE para a AE, com a alegação de que a arrecadação não é suficiente e devem ter outras prioridades. Mesmo nesse caso, como nos outros, o beneficiado tem autonomia para gerir os recursos da AE. Há também o oposto; municípios que bancam a AE com seus próprios recursos sem recorrer ao FNDE, e outros em que esses recursos federais são irrisórios comparados com aqueles que o município investe.

O PNAE garante alimentação de todos os alunos da educação básica matriculados em escolas públicas e filantrópicas. Os repasses são originários da União, para garantir que 20\% das necessidades diárias dos alunos sejam cumpridas são feitos 10 (dez) repasses em 10 parcelas mensais (de fevereiro a novembro) para a cobertura de 200 dias letivos, conforme o número de matriculados em cada rede de ensino.

Destarte, o valor repassado para a alimentação pelo programa pela União possui caráter complementar e não é suficiente por si só para garantir a qualidade dos cardápios elaborados pelos municípios. Nesse caso, cabe as EEx a complementação dos recursos financeiros transferidos pelo FNDE. 
Os programas de alimentação escolar realizados nos refeitórios das escolas, apesar dos esforços, deixam ainda muito a desejar. As decisões para que a alimentação escolar se efetive ficam restritas às políticas dos municípios que adotam procedimentos que dependem da sensibilidade e interesse político local. Não só, mas também porque os recursos financeiros repassados pelo PNAE sempre são insuficientes e como são complementares necessitam de verbas do orçamento municipal nem sempre disponíveis ou priorizadas para essa finalidade.

Esse artigo além da Introdução e das Considerações Finas, está dividido em 4 seções, a saber: Seção 2 trata dos aspectos introdutórios sobre o CAE; a seção 3 descreve a Composição do CAE, bem como destaca a sua forma de eleição e composição. Na parte 4, as atribuições e competências do CAE e por fim, na seção 5, trata-se dos desafios enfrentados pelos conselheiros no desenvolvimento de suas atividades.

Dessa forma, o objetivo do artigo é discorrer sobre o Conselho de Alimentação Escolar (CAE) em seus aspectos conceituais, legais e desafios no desenvolvimento das atribuições dos conselheiros. É um estudo de revisão bibliográfica, no qual foram utilizados sites de busca, como Google Acadêmico e SCIELO, através das palavras-chave: alimentação escolar, Conselho de alimentação escolar (CAE) e desafios. Com a pesquisa, foi possível levantar os dados que subsidiam esse estudo.

\section{Conselho de Alimentação Escolar (CAE): Aspectos Introdutórios}

A Constituição Federal de 1988, em seu artigo 208, instituiu que a educação é dever do Estado e que se efetiva por meio das três esferas de governo: União, estados e municípios. Nesse sentido, cada ente, tem responsabilidades específicas em relação ao Programa Nacional de Alimentação Escolar (PNAE) que são divididas: à administração pública cabe a execução; aos representantes da sociedade a fiscalização. Assim, a razão de existir do Conselho de Alimentação Escolar é verificar se as diretrizes do PNAE estão sendo executadas efetivamente.

Para Calasans e Santos (2013), no ano de 1994, teve início o processo de descentralização da AE, na qual funções de gestão passaram dos estados e municípios. Com a descentralização, evoluiu o processo da merenda, uma vez que ao assumirem todas as operações do programa, houve uma redução da corrupção e melhora na qualidade da alimentação servida aos alunos.

A descentralização permitiu racionalizar a logística e os custos de distribuição dos produtos, além de permitir que a escola ofereça uma alimentação escolar baseada nos hábitos da população nas diferentes localidades do País (Belik \& Chaim, 2009).

As compras institucionais descentralizadas também abriram a possibilidade de inserção da pequena empresa, do comércio local, do pequeno produtor agrícola e da pecuária local nesse mercado institucional, bem como a criação dos CAE que, por sua vez, possibilitou aos membros da comunidade escolar uma maior proximidade em relação à gestão do PNAE.

O Governo Federal, através da Lei 8.913 de 12/07/94, municipalizou a merenda escolar, transferindo diretamente para os municípios os recursos financeiros. Destarte, o processo de descentralização impulsionou a criação do CAE, que reforçava a participação da comunidade na fiscalização das atividades do programa (Vieira et al., 2008).

O CAE é um órgão colegiado que, de acordo com a Lei no 11.947/2009, regulamenta o atendimento da Alimentação Escolar aos alunos da Educação Básica. O artigo 18 da referida legislação dispõe que os Estados, o Distrito Federal e os Municípios instituirão, no âmbito de suas respectivas jurisdições administrativas, Conselhos de Alimentação Escolar - CAE, órgãos colegiados de caráter fiscalizador, permanente, deliberativo e de assessoramento.

O CAE tem caráter fiscalizador, pois desenvolve um acompanhamento e fiscalização do Programa. Essa inspeção deve ser independente para garantir a isenção na análise da execução do PNAE. Tem natureza permanente e não se extingue ou tem prazo determinado para terminar, funcionando durante todo o ano por tempo indeterminando. Ao afirmar que o CAE tem caráter deliberativo, a legislação garante que o colegiado tem a competência para decidir, em instância final, sobre 
determinadas questões no PNAE, como no caso da elaboração do parecer conclusivo (atribuição deliberativa). Já o assessoramento faz parte da atribuição consultiva do Conselho (PNAE, 2017).

No dicionário Aurélio, a palavra conselho significa "reunião de pessoas que busca deliberar ou solucionar um assunto". Já a origem etimológica vem do latim Consilium, que deriva do verbo consulo/consulere, que significa ouvir alguém quanto submeter algo a uma deliberação de alguém, após uma ponderação refletida, prudente e de bom-senso. O conselho tem a função de participar e colaborar com os destinos da sociedade (Cury, 2000).

Os Conselhos são uma forma de concretizar a participação da sociedade no controle social, com o fito de resguardar a democratização, uma vez que permite que os interesses da população estejam contemplados e atendidos por meio das políticas públicas. O conceito de controle social abrange o acompanhamento, fiscalização e análise por parte da sociedade sobre as ações do Estado (Balestrin \& Subdrack, 2019).

Os conselhos de políticas públicas são espaços democráticos, com o poder de verificar se a população que está sendo atendida por determinada política está de fato sendo favorecida. Os conselhos têm ainda a importante missão de intermediar os conflitos, uma vez que possuem uma composição plural e heterogênea, sendo representado pelos diferentes atores sociais, tais como a sociedade civil e o governo (Castro \& Dias, 2019).

O exercício das atividades desenvolvidas pelos conselheiros do CAE não é remunerado. Porém a Entidade Executora (Municípios e Estados) deve garantir infraestrutura adequada para o pleno funcionamento das atividades do CAE.

\section{Composição do Conselho de Alimentação Escolar (CAE)}

O CAE é composto por, no mínimo, 7 (sete) membros titulares e seus respectivos suplentes, sendo representantes do Poder Executivo, trabalhadores da educação e discentes, entidades civis e pais de alunos. A Resolução CD/FNDE n 26/2013 determina que os Conselhos de Alimentação Escolar tenham a composição mostrada na Figura 1.

Figura 1 - Composição do CAE.

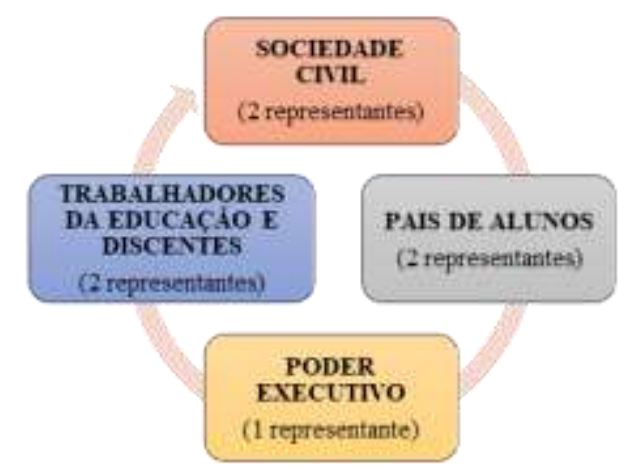

Fonte: art. 34 da Resolução CD/FNDE nº 26/2013.

De acordo com a resolução supramencionada, a composição do CAE é a seguinte: 1 (um) membro do Poder Executivo; que por sua vez não pode ser presidente; 2 (dois) membros docentes, discentes ou trabalhadores em educação, que são Indicados pelo órgão em assembleia específica, no qual o discente deve ser maior de 18 anos ou emancipado; 2 (dois) membros pais de alunos que são indicados por associação de pais e mestres em assembleia específica e 2 (dois) membros entidades civis, que são Indicados por entidades civis organizadas em assembleia específica.

A Resolução preconiza ainda, que cada membro titular do CAE terá um suplente do mesmo segmento representado, com exceção dos membros titulares "das entidades de trabalhadores da educação e de discentes", os quais poderão ter como suplentes qualquer uma das entidades referidas neste segmento. O membro suplente no exercício da titularidade terá as 
mesmas prerrogativas do titular. Os mandatos dos membros terão duração de quatro anos, podendo serem reeleitos de acordo com a indicação dos seus respectivos segmentos.

A presidência e a vice-presidência do CAE somente poderão ser exercidas pelos representantes das entidades de trabalhadores da educação de discentes, pais de alunos e membros indicados por entidades civis organizadas.

Nas entidades executoras com mais de 100 escolas da educação básica, a composição do CAE poderá conter até três vezes o número de membros, obedecida a proporcionalidade dos diferentes segmentos. A resolução em análise, recomenda que o CAE dos Estados e dos Municípios que possuam alunos matriculados em escolas localizadas em áreas indígenas ou em áreas remanescentes de quilombos, contenha em sua composição, pelo menos, um membro representante desses povos ou comunidades tradicionais.

A Resolução do Conselho Federal de Nutricionistas n 358/2005 destaca, em seu artigo $4^{\circ}$, que esses profissionais têm a função de assessorar o CAE, enaltecendo a importância da presença de nutricionistas no conselho. No entanto, alguns municípios entendem que essa participação vai na contramão da função fiscalizatória do CAE, uma vez que os nutricionistas estariam fiscalizando o seu próprio serviço. A presença desse profissional é de suma importância para o desenvolvimento das ações do PNAE (Balestrin \& Sudbrack, 2019).

\subsection{Escolha dos representantes e renovação do conselho de alimentação escolar (CAE)}

O FNDE (2020) disponibiliza uma cartilha que orienta os passos para a renovação dos gestores para composição do CAE. Entre os aspectos mais ressaltados pela cartilha está o conhecimento da sociedade sobre o Conselho e a ciência das atribuições, que tem o fito de garantir a efetiva participação de todos os membros durante o mandato. Sendo assim, é importante conhecer as atribuições do CAE; ter disponibilidade de tempo para frequentar as reuniões e realizar visitas às escolas, aos depósitos e às cozinhas centrais, quando for o caso; interesse no acompanhamento da execução do Programa e reconheçam a relevância social do trabalho como Conselheiro (FNDE, 2020).

Para o processo de renovação do mandato do CAE, os gestores não necessitam esperar até o dia do vencimento do mandato de 4 anos. O FNDE enviará uma correspondência à Entidade Executora, pelo menos 30 dias antes do vencimento do mandato do CAE, notificando a necessidade de providenciar a renovação do Conselho, sob pena de suspensão imediata dos repasses financeiros (UFRGS, 2014). São 7 os passos a serem seguidos para a renovação do CAE, como é mostrado na Figura 2.

Figura 2 - Esquema do passo a passo para a renovação do CAE.

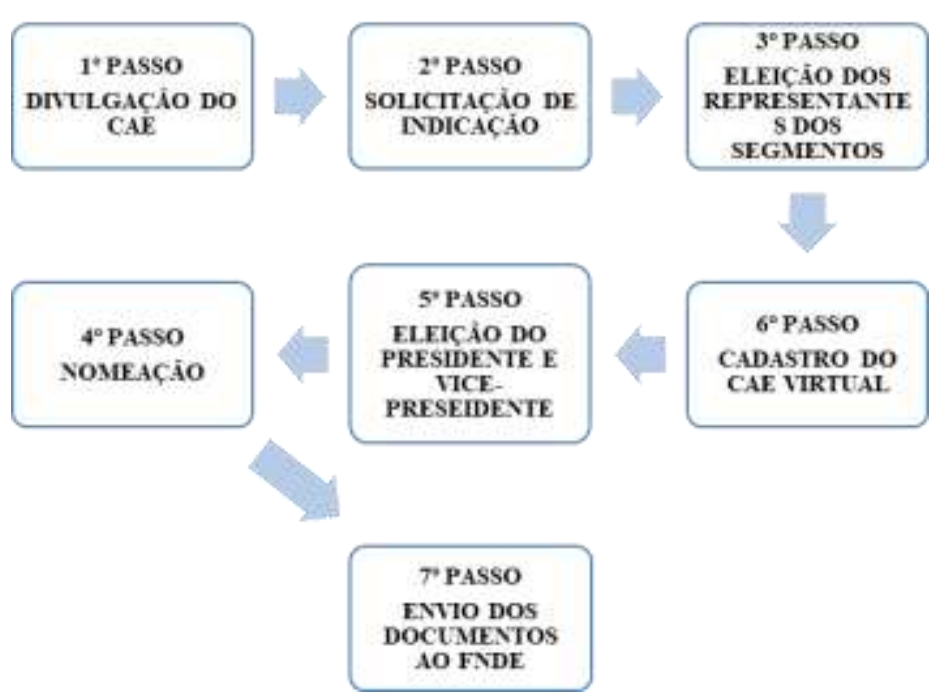

Fonte: UFRGS (2014). 
As Entidades Executoras (EEx), que são as Secretarias dos Estados, Municípios e Distrito Federal, num primeiro passo para a substituição de seus membros, deve iniciar a fase de mobilização e sensibilização, divulgando as ações do CAE, sua importância e atribuições para a comunidade escolar.

A EEX deverá realizar uma ampla divulgação do processo de renovação, realizando um chamamento público, seja por ofício, edital, carro de som e outros, visando ampla divulgação. Essa publicidade vai ao encontro do que preconiza a Constituição Federal de 1988 em seus artigos 37, caput, e art. 5, XIV (garantia de acesso à informação), XXXIII (obtenção de informações de interesse particular e geral perante os órgãos públicos e LX (publicidade dos atos processuais).

Tais princípios insculpidos na nossa Carta Magna de 1988 são primordiais para o controle da conduta dos agentes administrativos públicos, pois garantem fiscalizações e investigações constantes, bem como possibilitam que os cidadãos, monitorem e fiscalizem as prestações de contas no PNAE.

Os membros indicados em assembleias distintas para eleição de suas respectivas categorias, deverão se reunir com registro em ata (Profissionais da área de educação/alunos, pais de alunos e sociedade civil) e executivo indicado pelo prefeito (por meio de ofício). O nome dos eleitos deverá ser encaminhado para que o prefeito proceda à nomeação mediante portaria ou decreto.

A publicidade desses atos é de suma importância, uma vez que o cidadão só poderá atuar com qualidade se tiver acesso às informações públicas. Assim, a administração, observando o perfil da sociedade atual, deverá fazer uso também dos meios eletrônicos para difundir tais informações, tornando-as acessíveis a toda a população (Luz \& Benfatti, 2018).

O CAE terá vigência de 4 anos a partir da assinatura do Decreto ou Portaria de nomeação. Em ato contínuo, os eleitos em reunião específica tomarão posse e realizarão eleição do presidente e do vice-presidente. Todo o procedimento deverá ser registrado em ata para envio ao FNDE.

Os conselheiros, após nomeação, só poderão ser substituídos de acordo com a Resolução nº 38/2009/FNDE, artigo 34, §14, nas seguintes hipóteses: mediante renúncia expressa do conselheiro; por deliberação do segmento representado ou pelo descumprimento das disposições previstas no Regimento Interno de cada Conselho, desde que aprovada em reunião convocada para discutir esta pauta específica. O mandato do conselheiro substituto será complementar ao tempo restante daquele que foi substituído (FNDE, 2009).

\section{Atribuições e Competências Conselho de Alimentação Escolar (CAE)}

\subsection{Atribuições do conselho de alimentação escolar (CAE)}

As diretrizes da Alimentação Escolar, destacam que o Conselho de Alimentação Escolar (CAE) tem o caráter de controle social. Entre suas atribuições, está previsto o acompanhamento das ações realizadas pelas EEx, para garantir a oferta da alimentação escolar saudável e adequada e verificar se os recursos financeiros foram utilizados de acordo com o PNAE.

O CAE tem como objetivo zelar pela consolidação da alimentação escolar de qualidade por meio da fiscalização dos recursos públicos repassados pelo Fundo Nacional de Desenvolvimento da Educação (FNDE) para a execução do Programa Nacional de Alimentação Escolar - PNAE.

A Resolução 26 de agosto de 2013, artigo 35, destaca as atribuições do CAE, visto na Figura 3. 
Figura 3 - Atribuições do CAE.

\begin{tabular}{|c|c|}
\hline \multirow{7}{*}{$\begin{array}{l}\text { ATRIBUIÇOES } \\
\text { DO CAE }\end{array}$} & $\begin{array}{l}\text { Monitorar e fiscalizar a aplicaçào dos recursos e o cumprimento do disposto nas } \\
\text { diretrizes e na Resoluçâo n²0/2013 }\end{array}$ \\
\hline & Analisar o Relatório de Acompanhamento da Gestào do PNAE \\
\hline & $\begin{array}{l}\text { Analisar a prestação de contas do gestor e emitir Parecer Cosclusivo acerca da } \\
\text { execnçño do Programa }\end{array}$ \\
\hline & Realizar reuniăo especifica para apreciação da prestaçāo de contas \\
\hline & Elaborar o Regimento Interno e Plano de açâo \\
\hline & Fomecer informaçòes e apresentar relatórios de execuçào do PNAE \\
\hline & $\begin{array}{l}\text { Comunicar ao FNDE e órgàos de costrole qualquer irregularidade na execuçăo do } \\
\text { PNAE }\end{array}$ \\
\hline
\end{tabular}

Fonte: Resolução nº 26, de 17 de junho de 2013 (Brasil, 2013).

Observa-se que a resolução lista atribuições do CAE, enumera responsabilidades dos conselheiros e sinaliza que os membros detenham conhecimentos técnicos, noções de contabilidade e direito (lei de licitações e sobre a Lei 8.666/93). Tantas atribuições destinadas conselheiros constituem um rol excessivo de responsabilidades e competências para cidadãos comuns da sociedade. Dentre as atribuições mais importantes, destaca-se a análise da prestação de contas e a fiscalização dos recursos federais.

Caso as contas não sejam aprovadas pelo CAE, o FNDE avalia os documentos apresentados e, se concordar com o parecer do Conselho, inicia uma Tomada de Contas Especial e o repasse é suspenso. Essa medida também é adotada no caso de não apresentação da prestação de contas na forma e nos prazos estabelecidos na legislação (Brasil, 2013).

Em pesquisa realizada no Estado do Pará por Castro e Dias (2019) sobre a atuação dos conselhos alimentação, a falta de capacitação e treinamentos específicos para atuar como conselheiro do CAE foi apontado por 71,4\% dos sujeitos da pesquisa como um dos principais fatores que dificultam a execução dos trabalhos, sendo necessária a oferta de oficinas e treinamentos para a preparação desses conselheiros.

Esse contexto sinaliza para a necessidade imprescindível de qualificação do CAE, incluindo o preparo conceitual e sociopolítico de seus membros para o exercício de suas atribuições de maneira eficaz (Gallina et al., 2012).

Outra atribuição do CAE é a visita às escolas, na qual os mesmos terão a oportunidade de observar in loco se as exigências legais do PNAE estão sendo cumpridas.

Sobre esse aspecto, a cartilha fornecida aos conselheiros destaca condições de higiene do local onde os alimentos são guardados; como as refeições são preparadas e servidas (refeitório); as refeições servidas e o cardápio do dia; a quantidade de alunos que se alimentam; o desperdício de alimentos, o que pode indicar que os alunos não estão gostando da comida; a presença do teste de aceitabilidade e a organização de documentos, por exemplo, do controle de estoque de produtos. Após a visita, tudo o que não estiver de acordo, deve ser registrado e comunicado à Entidade Executora, buscando-se explicações e soluções, delimitando um prazo para as EEx sanarem as pendências (FNDE, 2017).

O CAE tem o um papel decisivo para o sucesso do PNAE. Deve haver uma parceira das EEx e o conselho, que deve ser visto como um parceiro que auxilia na execução do programa, apontando sugestões e soluções para os problemas, e não como um conselho que serve apenas para apontar os falhas e irregularidades.

A Resolução do FNDE nº 26/2013 também apresenta como atribuições do CAE a elaboração do Plano de Ação anual, que é um documento que dispõe sobre as atividades a serem desempenhadas pelos membros do conselho, no ano em curso e/ou no ano subsequente, a fim de acompanhar a execução do PNAE nas escolas. Cabe salientar que não há regras ou listas 
obrigatórias de atividades que devem constar no Plano de Ação, pois o mesmo deve refletir a realidade de cada município, respeitando as necessidades e a autonomia de cada CAE (FNDE, 2019).

O CAE, além das atribuições descritas, por força da Lei $\mathrm{n}^{\circ} 11.947 / 2009$, tem ainda a tarefa de assegurar o fortalecimento da Agricultura Familiar, que trouxe garantias e critérios que asseguram que no mínimo 30\% dos recursos repassados para estados e municípios serão destinados à compra direta de alimentos provenientes da agricultura familiar.

\subsection{Competências do conselho de alimentação escolar (CAE)}

Além das atribuições da Resolução do FNDE nº 26/2013, o artigo 19 da Lei no 11.947/2009, estabelece 4 competências aos membros do CAE: acompanhar e fiscalizar o cumprimento das diretrizes da alimentação escolar; acompanhar e fiscalizar a aplicação dos recursos; zelar pela qualidade dos alimentos, em especial quanto às condições higiênicas, bem como a aceitabilidade dos cardápios oferecidos e receber o relatório anual de gestão do PNAE e emitir parecer conclusivo a respeito, aprovando ou reprovando a execução do Programa (Brasil, 2009).

Em consonância com as atribuições, os conselheiros têm definidas pela lei competências que o legitimam e lhe conferem autoridade para acompanhar e julgar de forma efetiva a aplicação dos recursos do PNAE.

No momento em que os conselheiros atuam de forma efetiva, há um aumento da transparência administrativa dos governos, e as decisões passam a caminhar para uma direção da democratização de direitos (Castro \& Dias, 2019).

Nesse sentido, fica clara a importância do papel dos conselheiros no controle dos recursos enviados paras as EEx pelo FNDE e consequentemente no desenvolvimento da democracia garantida constitucionalmente pela Constituição de 1988, uma vez que o CAE tem competências para supervisionar as rotinas e os trâmites da alimentação escolar, exercendo o papel de controle social, ou seja, os membros do CAE são os representantes legítimos da sociedade civil na tarefa de fiscalizar tais recursos e de alocar a sociedade dentro do processo de tomada de decisões.

\section{Desafios à Atuação dos Conselhos de Alimentação Escolar (CAE)}

No ano de 2018, foi desenvolvida uma pesquisa pelo FNDE para que por meio de uma amostra, com o objetivo de desenhar o perfil dos conselheiros de alimentação escolar no Brasil. Os dados revelam que a maioria dos conselhos é constituída por mulheres (75\%) e a faixa etária predominante é de 46 a 60 anos (55\%). Quanto ao nível de escolaridade dos conselheiros, da amostra tem curso superior com graduação e pós-graduação (74\%). Existem conselheiros com títulos de mestre e doutores (FNDE, 2018).

Chama a atenção a predominância feminina no CAE. Observa-se que a representação por mulheres dos conselhos de políticas públicas é bem maior, quando comparados à representação política nos poderes Executivo e Legislativo. A presença majoritária das mulheres nesse conselho pode estar relacionada às características femininas como a competência e sensibilidade com temas sociais (Souza et al., 2019).

Em relação à ocupação dos membros do $\mathrm{CAE}, 4,58 \%$ são profissionais autônomos; 3,96\% trabalham em empresa privada; 2,88\% aposentados e $82 \%$ da amostra é constituída de funcionários públicos, o que não surpreende, já que os segmentos dos trabalhadores de educação bem como os do poder executivo são funcionários da Entidade Executora. (FNDE, 2018).

Em outra pesquisa realizada sobre a atuação dos conselhos de alimentação escolar no Estado do Pará, constatou-se que as principais dificuldades apresentadas relativas à atuação dos conselheiros no exercício de suas atribuições foram a falta de recursos financeiros, falta de capacitação e treinamentos adequados (Castro \& Dias, 2019).

$\mathrm{O}$ desafio da falta de apoio financeiro das EEx para desenvolver os trabalhos do CAE é um problema que implica diretamente no desenvolvimento da execução dos trabalhos dos conselheiros, pois atribuições importantes como apoio de 
transporte para visitação as escolas, falta de local adequado para realização das reuniões e falta de treinamentos e capacitação, que são assegurados pela Resolução FNDE nº 26/2013, impossibilitam o trabalho dos conselheiros.

O efetivo preparo e envolvimento dos conselheiros, bem como suas adequadas condições de trabalho são fatores imprescindíveis para o êxito do PNAE (Souza, et al., 2019).

A falta de preparação e conhecimento da legislação sobre o PNAE é um dos desafios mais difíceis de serem contornados, uma vez que na prática não são ofertados cursos voltados para a preparação dos conselheiros para atuar no CAE. Já descrevemos as inúmeras atribuições e competências impostas aos conselheiros, devendo ter conhecimentos de direito, contabilidade, dentre outros. Sem esse efetivo conhecimento, o trabalho fica impossibilitado.

O CAE, constituído de pessoas que dominam as suas diretrizes, é um mecanismo de articulação política entre as EEx, corroborando as perspectivas acerca da intersetorialidade e melhorando o desempenho institucional (Pinheiro \& Araújo, 2017).

Uma pesquisa realizada em dois Estados (Minas Gerias e Espírito Santo) revelou que 76,9\% dos conselheiros nunca participaram de cursos de capacitação para atuar como parte do CAE. Programas de formação merecem destaque para os atuais e futuros conselheiros (Souza, et al., 2019)

A falta de qualificação pode ser apontada como um dos maiores desafios enfrentados pelos conselheiros, como bem afirma Castro, Silva, Dias e Schimith, (2020), que a falta de qualificação pode ser um ponto crítico para o sucesso da atuação do $\mathrm{CAE}$, pois se o conselheiro não possui conhecimento necessário para identificar as irregularidades, não poderá tuar de forma satisfatória.

Vale destacar que historicamente a criação do CAE se deu por exigência legal e não por organização voluntária da sociedade. Assim, a escolha dos membros do CAE é definida em lei.

Destarte, a escolha dos representantes de cada segmento requer eleição específica da respectiva categoria, sendo possível nessa escolha existir a articulação política, a barganha de favores e a pressão na escolha dos membros do colegiado, que podem interferir nas atribuições e desenvolvimento das atividades do CAE.

Nesse sentido, deve-se evitar a transformação do conselho em locus de deliberação governamental, que passe por cima da autonomia conselhista, diminuindo a efetividade do seu poder de decisão ou atrelando-as aos interesses do poder público ou dos arranjos políticos (Pinheiro \& Araújo, 2017).

Assim, os conselheiros precisam pensar na coletividade, agir no coletivo e com intensões voltadas ao coletivo e não por influência político-partidária ou por interesses individuais ou por imposição (Balestrin \& Sudbrack, 2019).

Não se pode deixar de mencionar como um desafio a falta de interesse pela sociedade civil de participar da composição do CAE, que pode estar ligado à forma como se dá o processo de mobilização e a publicidade das ações do CAE.

Deve-se refletir sobre a importância da participação da comunidade, uma vez que é uma oportunidade do pai ter conhecimento do que seu filho come na escola, bem como fiscalizar como são transferidos os recursos pelo FNDE e observar as possíveis irregularidades do processo e denunciá-las.

De forma resumida, pode-se levantar que são muitos os desafios provenientes no desenvolvimento das ações do CAE, tais como falta de conhecimento dos conselheiros, falta de ajuda financeira das EEx, falta de interesse da sociedade civil em participar do CAE, não deixar que as decisões do conselho sofram influência político-partidária. Vejamos que são inúmeros os desafios a serem contornados, mas todos passíveis de serem solucionados, pois só dependem da iniciativa e boa vontade da gestão pública. 


\section{Considerações Finais}

O PNAE, apesar dos avanços dos últimos anos, ainda tem muitos desafios a serem enfrentados pelo CAE. Suas ações devem ser planejadas e revisadas, conforme estudos apresentados, observando as referências legais do PNAE. Há também uma necessidade de viabilizar as condições adequadas para que essas ações se concretizem.

Reforça-se a importância da formação do conselheiro com o objetivo de aprimorar a atuação do CAE. Sugere-se que seja ofertada de maneira permanente cursos de formação inicial e continuada para os conselheiros a fim de que tenham conhecimento de suas atribuições e competências como membros do CAE, pois só a qualificação viabilizará um trabalho efetivo.

A atuação dos conselheiros deve ser livre de amarras político-partidárias, pois tal fato pode afetar a validade das ações do conselho, uma vez que o CAE deve atuar de maneira isenta, como forma de garantir que sua participação cumpra a função de controle social.

Além disso, destaca-se a necessidade de atuação interligada entre o CAE e EEx, pois essa parceria é fundamental para a garantia da segurança alimentar e nutricional. As EEx não podem ter a concepção de que o CAE é um inimigo, mas sim um aliado importante.

O CAE deve voltar suas atenções para a fiscalização da qualidade das refeições servidas nas escolas, bem como controlar a utilização dos recursos públicos por meio de visitas nas escolas e análise minuciosa da prestação de contas. Essas duas ações são essenciais para os conselheiros.

Destaca-se que o trabalho desenvolvido pelo CAE é voluntário e deve ser considerado um exercício de cidadania, uma oportunidade de exercer a democracia e garantir o controle social de uma das políticas públicas de alimentação mais importantes do país, sendo a sua participação no CAE uma admirável contribuição social.

Por fim, espera-se que esse estudo contribua para o aperfeiçoamento de estudos relacionados à alimentação escolar e à importância do CAE, contribuindo para a melhoria da gestão do PNAE e a efetividade do programa.

\section{Referencias}

Belik, W., \& Chaim, N. A. (2009). O programa nacional de alimentação escolar e a gestão municipal: eficiência administrativa, controle social e desenvolvimento local. Revista Nutrição. Campinas, 22(5):595-607. http://dx.doi.org/10.1590/S1415-52732009000500001.

Constituição da República Federativa do Brasil de 1988. Promulgada em 5 de outubro de 1988. http://www.planalto.gov.br/ccivil_03/C onstituicao/Constituicao.htm.

Lei $n^{\circ} 8.913$ de 12 de julho de 1994. Dispõe sobre a municipalização da merenda escolar. Recuperado de http://www.planalto.gov.br/ccivil_03/leis/18913.htm.

Lei $n^{\circ} 11.947$, de 16 de junho de 2009. Dispõe sobre o atendimento da alimentação escolar e do Programa Dinheiro Direto na Escola aos alunos da educação básica. http://www.planalto.gov.br/ccivil_03/_Ato2007-2010/2009/Lei/L11947.htm.

Resolução $n^{\circ} 26$ de 17 de junho de 2013. Dispõe sobre o atendimento da alimentação escolar aos alunos da educação básica no âmbito do Programa Nacional de Alimentação Escolar - PNAE. https://www.fnde.gov.br/acesso-a-informacao/institucional/legislacao/item/4620-resolu\%C3\%A7\%C3\%A3o-cd-fnden\% $2 \%$ BA-26,-de-17-de-junho-de-2013.

Castro, H. A. S., \& Dias, L. N. S. (2019). Atuação dos conselhos de alimentação escolar no estado do Pará. X Colóquio Organizações, Desenvolvimento e Sustentabilidade - CODS, Belém, Pará. http://revistas.unama.br/index.php/coloquio/article/view/1725.

Castro, H. A. S., Silva, E. J., \& Dias, L. N. S. Schimith, C. D. (2020) Desafios à atuação dos conselhos de alimentação escolar. Amazon, Organizations and Sustainability. 9 (2). http://revistas.unama.br/index.php/coloquio/article/view/1725/pdf.

Cury, C. R. J. (2006). Conselhos de educação: fundamentos e funções. Revista Brasileira de Política e Administração da Educação (RBPAE), Porto Alegre, 22(1):41-67. https://doi.org/10.21573/vol22n12006.18721.

Ferreira, N. S. C., \& Aguiar, M. A. (2000). Gestão da Educação: impasses, perspectivas e compromissos. São Paulo: Cortez.

Universidade Federal do Rio Grande do Sul-UFRGS - Centro Colaborador em Alimentação e Nutrição do Escolar da (CECANE). (2014). Passo a Passo para a Composição do CAE. http://www2.ufrb.edu.br/cecane/projeto-mais-mercado/category/12-manuais-cartilhas?download=53:2-relatrio-final-2013-2014apndice-iii-produto-2-passo. 
Research, Society and Development, v. 10, n. 3, e35510313405, 2021

(CC BY 4.0) | ISSN 2525-3409 | DOI: http://dx.doi.org/10.33448/rsd-v10i3.13405

Fundo Nacional de Desenvolvimento da Educação (FNDE). Informe CAE O1/2019 Plano de Ação do CAE. http://sites.bauru.sp.gov.br/arquivos/website_cme/CAE/Documentos//Plano\%20de\%20A\%C3\%A7\%C3\%A3o\%20Cae\%202019.pdf.

Fundo Nacional de Desenvolvimento da Educação (FNDE). Passos para a renovação do CAE. https://www.fnde.gov.br/index.php/programas/pnae/pnae-areagestores/pnae-manuais-cartilhas/item/11036-passos-para-a-renovca\%C3\%A7\%C3\%A3o-do-cae

Gallina, et al. (2012). Representações sobre segurança alimentar e nutricional nos discursos de um Conselho de Alimentação Escolar Saúde soc. 21(1). http://www.scielo.br/scielo.php?pid=S0104-12902012000100010\&script=sci_arttext\&tlng=pt

Luz, H. I. M., \& Benfatti, F. F. N. (2018). Democracia participativa na administração pública e a importância do princípio da publicidade. Revista Eletrônica da Faculdade de Direito de Franca. 13(1):43-60. Acesso em: https://doi.org/10.21207/1983.4225.718

PNAE (2017). Cartilha para Conselheiros do Programa Nacional de Alimentação Escolar (PNAE). https://www.fnde.gov.br/index.php/programas/pnae/pnaearea-gestores/pnae-manuais-cartilhas/item/11037-cartilha-para-conselheiros-do-programa-nacional-de-alimenta\%C3\%A7\%C3\%A3o-escolar-pnae.

Souza Pinheiro, C., \& Cassiano de Araujo, C. (2018). Controle social, participação popular e seus desafios no programa nacional de alimentação escolar (PNAE): uma análise dos conselhos de alimentação escolar (CAE) de dois municípios sergipanos. Alamedas, 5(2). https://doi.org/10.48075/ra.v5i2.17123

Vieira, M. N. C. M. et al. (2008). Gestão de um Programa de Alimentação Escolar em um Município Paulista. Segurança Alimentar e Nutricional. 15 (1): 2948. https://www.arca.fiocruz.br/handle/icict/271 